\title{
Getting Stuff Done: Comparing E-mail Requests from Students in Higher Education in Britain and Australia
}

\author{
Andrew John Merrison*a ${ }^{*}$, Jack J. Wilson ${ }^{\mathrm{a}}$, Bethan L. Davies ${ }^{\mathrm{b}}$ and Michael Haugh ${ }^{\mathrm{c}}$ \\ ( ${ }^{\mathrm{a}}$ York St John University, ${ }^{\mathrm{b}}$ University of Leeds, ${ }^{\mathrm{c}}$ Griffith University)
}

\begin{abstract}
:
A small corpus of student e-mail requests to academic staff in a British and an Australian university was collected in order to investigate the cross-cultural nature of Englishes in these requesting events. The notions of ACCOUNT and BUT-JUSTIFICATION, together with the concepts of EQUITY and EQUILIBRIUM are used to explicate the distribution of various features associated with these requests. Results indicate that the British data orient to deferential DEPENDENCE whereas the Australian data exhibit interdependent EGALITARIANISM. Finally, the process of our analysis brings to light the fact that we ought to refine Heider's (1958) theory of OBLIGATION and this, we do. The overall claims of this paper are that the situated nature of student e-mail requests can have a great bearing on the discursive construction of student identities, that this has a bearing on how things get done, and that how things get done in different varieties of English merits further investigation.
\end{abstract}

\section{Keywords:}

Englishes; e-mail; requests; accounts; equity and equilibrium; obligation

\section{Introduction}

In our experience, a not inconsiderable portion of our e-mail traffic involves students asking lecturers to do things for them: provide them with job references, excuse them for their absence in class, send them handouts, meet with them, grant them extensions, offer supportive reassurance, and so forth. Following on from an earlier detailed analysis of e-mail requests sent within a British university (Merrison and Davies, 2007), the intention of the current paper is to expand our focus beyond a British English context and to investigate whether and to what extent the findings from that data are replicated in other varieties of English. Consequently, this paper offers a cross-cultural comparative analysis of a corpus of student e-mails sent to academic staff at universities in Northern England and Queensland, Australia, with a view to answering recent calls for more attention to be paid to differences in pragmatics across varieties of English.

The focus of this paper is on the speech act of requests and how they are constructed within the medium of e-mail. While we are evidently taking a 'speech act' approach in identifying these data, we also draw on analytic techniques from across im/politeness theory, including some basic tenets of conversation analysis. In particular, we take a data-driven approach to the phenomena: the categories we identify arise from the data and are made relevant in that data. However, we take a more discourse-analytic approach in the application of those categories where, like the model proposed by Blum-Kulka, House and Kasper (1989), we seek to account for all parts of the requestive speech act and recognise the 'work' each part does in the production of the overall discourse event. Thus, rather than consider requests as context-free head ${ }^{1}$ (main) acts, we recognise - and indeed value - the

\footnotetext{
${ }^{1}$ The 'head act' is that part of a speech act which performs the essential illocutionary force of an utterance and which is able to stand alone. Head acts can be 'built' into more complex discursive acts in two ways. Internal modification is the syntactic and/or lexical modification of the linguistic material which realises the head act. External modification is the use of extra acts, outwith the head act, which support the business of the head act (after Blum-Kulka, House and Kasper, 1989).
} 
fundamental importance of the situated nature of their production. For us, this concern manifests itself in recognising that support for head acts may occur both externally to the request as well as internally. Our analysis focuses on the linguistic material which externally modifies these head acts and we use the notions of accounts, but-justifications, equity, equilibrium and obligation to explicate the patterns of these features within the requesting events in our British and Australian corpora. The purpose of the current paper is to explore whether (and to what extent) the same patterns hold for both these cultural sites. ${ }^{2}$

While both British and Australian cultures recognise English as their dominant language, we argue that the situated nature of politeness means that subtle cultural differences in society at large and the higher education systems in particular will affect and thus shape the way in which Australian and British students discursively construct their requests and also their student identities. It is our thesis that such delicate discursive work will illuminate interesting cross-cultural differences within languages as well as across them. The degree of perceived entitlement to make different types of request acts - and thus the ways in which a request event itself is constructed in e-mails - is of course inevitably afforded and constrained by organisational and policy differences between institutions (Wardvogel, 2007), and the nature of preceding online (and offline) interactions between the lecturers and students (Bunz and Campbell, 2004:11; Jensen 2009:16). Our view is that the degree of perceived entitlement to make a requesting act is thus inherent within the construction of the entire requesting event, along with an orientation to the contingencies that may be involved in the recipient granting that request (Curl and Drew 2008: 130). However, while these requests inevitably arise in local, situated contexts, and should be analysed as such, we argue that a focus on localised factors such as (perceived) entitlement and contingency cannot adequately account on their own for the systematic differences in the design of these request events between the British and Australian corpora. We suggest that the British data display an overall orientation towards deferential dependence, while the Australian data display an overwhelming orientation towards interdependent egalitarianism, as users modulate their display of perceived entitlement to make different kinds of requests. We further argue that it is this differential orienting to dependence and egalitarianism that provides a compelling account of the differences between the two corpora that complements our appeal to the localised orientations of users to perceived entitlements and contingencies. Student e-mail requests are indeed accomplished in localised, situated contexts, but are also, we argue, designed within a broader societal milieu, where although there is a common language, there are also arguably systematic cultural differences. We justify this claim through an analysis of two matched datasets of student e-mail requests that is grounded in interactional sociolinguistics/pragmatics, that is, an approach that is informed by methods and research in Conversation Analysis (CA), but which also makes appeals to ethnographic data and analytical categories that traditionally lie outside the purview of CA (Haugh 2012). While our analytical categories draw from speech act theory, these categories are significantly modified or even supplemented with new categories to make our analysis consistent with the methodological commitments of interactional sociolinguistics/pragmatics, as well as to accommodate the specific contingencies of e-mail as opposed to face-to-face interactional data.

Before engaging with these particular issues, however, we first consider key literature on requests, accounts, but-justifications, equity and equilibrium. This is followed in section three by an outline of our methodology. In section four, we provide examples of the various

\footnotetext{
${ }^{2}$ By 'culture', naturally we cannot expect to claim that any of our findings necessarily generalise beyond these particular students in these particular universities interacting with these particular faculty members - to do so would require further research - but our intuition is that there is nothing particularly special about the situations whence our data come.
} 
categories of interest and present the most notable quantitative findings. Section five discusses the implications of these for students' construction of both their own identities and the staff-student relationship. Finally, in section six, we conclude by showing how our results relate to Heider's notion of ought forces, which we now move to discuss.

\section{Previous Literature}

\subsection{Getting stuff done: requests}

We start from the following premise, that language is about doing:

Language does not deliver meanings. Language delivers actions. (Drew, 2009)

Language is used for doing things. [...] Language use is really a form of joint action [...] that is carried out by an ensemble of people acting in coordination with each other.

(Clark, 1996:3, original emphasis)

But not only is language used for doing things, one of those doings (if the conditions are right) can be getting others to do things: in the words of Heider (1958:244), "One $[p]$ can induce another $[o]$ to do something $[x]$ by producing conditions of action in the other person" - and it is these conditions which make $o$ feel as though they are obligated (as though they ought) to act in a certain way. This inducement to act is what Austin (1975 [1962]) might have called an 'exercitive', what Searle (1979 [1975]) has called a 'directive', and what we, in this paper, simply call a request.

Secondly, we assume that humans are, for the most part, rational agents (Davies, 2007; cf. (inter alia) Brown and Levinson, 1987; Clark, 1996; Grice, 1975; Searle, 2001). For the purposes of the current paper, a related assumption is that it would be irrational for anyone to make a (non-ostensible) request if they genuinely believed that they are unlikely to benefit in some way from the request act (whether or not it achieves its immediate goal(s)).

Thirdly, we take the view that the particular design of the sequential and componential structure of requests in situated contexts is used to accomplish both identity and relational work (Ho, 2010; Jensen, 2009; Rogers and Lee-Wong, 2003). Ho (2010:2253), for instance, argues that "apart from getting the recipients to comply with the request, the e-mail authors also constructed for themselves some desirable personal identities by drawing the e-mail recipients' attention to some of their particular self-aspects through the e-mail discourse". This identity work is not separate to relational concerns in designing requests, but intersects, and is at times even in dynamic tension, with identity concerns (Jensen 2009:16; Rogers and Lee-Wong 2003:396).

However, we argue that the various ways in which requests can be constructed or framed should not be straightforwardly equated with im/politeness. While speakers (or in this case writers) may attempt to index a recognisably im/polite stance in designing a request, this is not necessarily how the request may be evaluated by the addressee or recipient. Interactants may converge or diverge in their evaluations of actions, including requests, as im/polite (Arundale, 2006; Eelen, 2001; Haugh, 2007; Mills, 2003; Watts, 2003). Yet while acknowledging the inherent discursivity of im/politeness, we nevertheless argue that interactants can only hold one another accountable for such evaluations in light of empirical and moral norms relative to which these evaluations arise. Empirical norms are defined here as encompassing (linguistic) behaviour that interactants think is likely to be occasioned in particular, localised contexts based on the sum of their individual experiences, while moral norms are defined as involving (linguistic) behaviour interactants think should be occasioned, 
with the latter being a part of the moral structures of sociocultural networks (Culpeper 2008:29; Haugh 2003:399-400; cf. Eelen 2001:127-158; see also Hambling-Jones and Merrison this issue, §2.1). In order to establish what constitutes recognisably im/polite stances, then, a better understanding of the empirical norms of situated request design is in order.

It is therefore the design of requests (speech acts) situated within e-mails (speech events) from students to academic staff rather than evaluations by academics of those e-mails that is the focus of the current paper. In essence, we are concerned with the various ways in which the requester $[p]$ attempts to make their recipient $[o]$ feel more obligated to accede (what Heider (1958) would have called $p$ inducing ought forces in $o$ ).

Having set out our intended destination, as well as our assumed point(s) of departure, we are now in a position to cover some of the main literature on which our analysis rests.

\subsubsection{Getting stuff done offline}

It is Blum-Kulka, House and Kasper (1989b) who are perhaps most widely cited in the request literature for their Cross-Cultural Speech Act Realization Project (CCSARP). This research explored the view that culturally specific features create culturally specific interactional styles, and that these features will be realised through speech acts (Blum-Kulka, House and Kasper, 1989a:7). They collected data on requests and apologies using Discourse Completion Tasks (DCTs) - a method designed to elicit the very speech acts of interest. Elicitation was achieved by respondents being given both a description of the situational background and a response to the missing turn that they must fill in, consequently creating artificial situations. These, Blum-Kulka, House and Kasper (1989a) argue, not only avoid the observer's paradox but also elicit the "stereotyped aspect of speech behavior [...] need[ed] for cross-cultural comparability" (p.13).

We would maintain that there are serious limitations to the type of data that can be elicited by such means: in promoting elicited stereotypical responses it risks homogenising the data rather than allowing the heterogeneity of language to emerge. In a recent study of requests in e-mail gathered through written DCTs, for instance, Woodfield and EconomidouKogetsidis (2010) focused their analysis on mitigation strategies. The most common e-mail request structure identified in their data was a request head act mitigated internally through conditional structures, tense and/or consultative devices and externally through grounders (pp.93-99), in other words, a stereotypical indirect speech act move. While acknowledging the existence of other discourse strategies, such as "orientation moves" to establish shared knowledge and thus grounds for solidarity between the sender and receiver, they only found one example of the use of such a strategy in their entire corpus of 176 requests (Woodfield and Economidou-Kogetsidis, 2010:101). However, the limited employment of orientation or solidarity moves in the requests elicited through DCTs found in this study seems to us to be most likely an artifact of a methodology which does not employ naturally-occurring e-mail data (where students have a very real investment in getting stuff done) rather than reflecting differences between the cohort of participants in our study and theirs. Or at least there is no way to be sure that what the students write in the DCT is how they would really make such requests, and so no way to make a reasonable comparison. Since e-mail data is relatively easy to harvest there seems to be no reason, in our view, to persist in gathering data that throws up such problems.

Nevertheless, Blum-Kulka, House and Kasper's (1989a) analysis does offer useful distinctions between the various linguistic strategies employed when making requests and it is on these that we have based our current research. Their analysis involved a dissection of internal modification and supportive moves (external modification). Internal modification 
included: minimisers (just, quick, a little); conditionality (wondering, if); deontic/epistemic modality (possible, perhaps, may); as well as lexis relating to ingratiation and gratitude (please, thanks). External modification included the use of: grounders (or what we are calling ACCOUNTS $^{3}$ ); disarmers (classified here as either APOLOGIES or appeals to COMMON GROUND); promises of reward (or what we are calling VIRTUAL GIFTS/APPRECIATIONS), and upgraders (or what we term here AGGRAVATORS).

Curl and Drew (2008) also explore the internal modification of requests. They investigated two corpora of recorded conversational data, one of ordinary everyday conversation (between friends and family), the other of out-of-hours institutional conversation (between patients - or at least someone on behalf of the patient - and doctors). More specifically, they focus on the difference between requests prefaced by "Would/could you ..." and "I wonder if..." and the effect this may have in terms of "speakers" orientations to their entitlement to ask, and the contingencies that may be associated with granting the request (e.g., doing what is asked)" (Curl and Drew, 2008:134). This emphasises their concern with the syntactic properties internal to the request itself (the speech $a c t$ ), whereas our focus has expanded to include the external modification of the entire e-mail request (the speech event).

\subsubsection{Getting stuff done online}

What e-mail requests offer is an opportunity for $p$ (the sender) to design, edit and revise their request $(x)$ before sending (Biesenbach-Lucas, 2007; Duthler, 2006; Herring, 2002), effectively creating a situation where the requester can attempt to construct a more idealised locution in order to get $o$ (the recipient) to be maximally compliant.

Duthler (2006) compared requests that students made to a (hypothetical) member of academic faculty using e-mail with those using voice-mail. He did so not in an attempt to investigate institutionalised requests but rather to "measure the effect of communication technology on the construction of requests" (2006:11). Duthler categorised his data into address phrase, request for the meeting, request for reply and adjunct phrases and subsequently made correlations between these sections, the level of imposition and the mode of communication used.

\footnotetext{
${ }^{3}$ While words in SMALL CAPS in this paper are invariably everyday terms, we use this typographical convention to indicate their status as analytical categories in our research. While we do provide definitions for these categories (below), it is important that they are not to be taken as being necessarily synonymous with their quotidian meanings.
} 
Although his methodology involved direct experimentation (where the students were told to make requests for meetings with an unknown professor, thereby creating an unnatural environment), Duthler's (2006:13) results that e-mail requests incorporated more adjunct phrases than voicemails (and thus supported his hypothesis of greater politeness in e-mails) offer us two main useable conclusions: (i) the asynchronicity of e-mails allows requesters time to design their requests and also to make revisions; and (ii) an increased number of strategies not only mitigates an offence but also attempts to minimise any right to refuse it. Biesenbach-Lucas (2007), following Blum-Kulka, House and Kasper (1989a), also explored the relationship between severity of the imposition and the structural properties it elicits, focussing on the internal modification of request strategies of non-native and native speakers of English within a single context. While we are interested in external features found in native speakers within different contexts, we would concur with her (2007:74, original italics) appreciation that if speakers of a language "have flexible linguistic means at their disposal and know which linguistic structures and politeness devices to use" then "email technology $[\ldots]$ allows writers to plan and revise messages before sending them, thus affording the opportunity to edit not only for grammar and mechanics, but also for pragmatic clarity and politeness" (2007:59).

Other studies have investigated request e-mails sent by non-native second language speakers of English to members of staff (Woodfield and Economidou-Kogetsidis, 2010; Economidou-Kogetsidis, 2011), or request e-mails sent amongst staff in an educational institution in Hong Kong (Ho, 2010, 2011). Although our current study differs in certain respects from these, they do offer a useful insight, viz. the notion of plan-ability within asynchronous communication. This plays a key role in our analysis, and, we would claim, should do so in any analysis of e-mail interaction.

\subsubsection{Summary}

In contrast to a face-to-face interaction, the author of an e-mail request does not necessarily have the ability to build it delicately over a series of turns. This creates a situation where they have to make their request and attempt to limit any offence it may cause within the single speech event - they have just one attempt to make good their request. This is what we (following Clark, 1996) refer to as a one-shot process whereby $p$ must (if rational and able) assume the disposition and value systems of $o$ and act in a way which orients to these in order to achieve their request-goals ( $x$ ) (cf. Schelling, 1960). Effectively then, these e-mails are evidence of Recipient/Audience Design par excellence. Furthermore, the requester also has no access to the inventory of paralinguistic devices that are available in face-to-face interaction. ${ }^{4}$ This fact, combined with the overall 'one-shot-ness', means that any subtle mitigating work needs to be carefully considered and built into the design of the e-mail. Such considered behaviour(s) can only emphasise the norms of conduct within the specific Community of Practice ('CofP') (Eckert and McConnell-Ginet, 1992; Wenger, 1998) where these requests are employed. We therefore suggest that collecting data via our method offers the opportunity to explore the prototypical rather than stereotypical behaviour (cf. BlumKulka, House and Kasper, 1989a) and additionally achieves the criterion of 'natural conditions' that Blum-Kulka, House and Kasper (1989a) sought, but we would argue, did not attain.

\subsection{Doing Mitigation: ACCOUNTS}

\footnotetext{
${ }^{4}$ Although emoticons and the like can be used to index emotive or attitudinal stances in making requests in emails (Fukushima, 2008), there were very few examples of this in the data analysed here.
} 
In this section, we briefly acknowledge some of the existing literature on accounts. This brevity is based on our assumption that the broad concept of accounts/accountability is sufficiently understood within the field. Our main aim here, then, is to justify why we have not simply adopted any of the previous typologies that were already available 'off the shelf'.

Starting in the mid 20th century, some of the first to be interested in the nature of accounts were the philosopher, Austin (1961 [1956]) and the social psychologist, Heider (1958). For us, Heider's most salient interest was in the "attribution of events to causal sources" (1958:16) - a notion pertinent to any exploration of interaction (cf. the conversation analytic mantra: 'Why that now?'). He distinguished between two main sources of attribution: personal sources, which are claimed when the individual in question is personally responsible - they are culpable; and environmental sources, when the "environment is held accountable" - the event happened but it is the situation that is to blame (1958:89).

Austin's (1961 [1956]) contribution focused on introducing a distinction between accounts as justifications and accounts as excuses, a distinction consistent with Heider's. In essence, the difference is this: justifications are used when an individual accepts that an untoward event has been attributed to them and therefore requires explanation, however, they feel that "the special circumstances of the occasion" are to be held responsible (op cit.:124). On the other hand, excuses imply that the individual accepts not only the existence of the event but, moreover, their culpability for it. As Austin (1961 [1956]:129) suggests, "If ordinary language is to be our guide, it is to evade responsibility, or full responsibility, that we most often make excuses" because it is via excuses that the perpetrator attempts to mitigate (minimise, or even refute) the negative implications the offence may have on their overall identity/face.

More recently, the volumes by Semin and Manstead (1983) and Benoit (1995, and the many references he cites on pp.51-61) offer a wide range of possible taxonomies of accounting behaviours. Schönbach (1990), for example, has a categorisation which has 122 sub-classifications of concessions, excuses, justifications and refusals - each of which ending with a catch-all 'other' category. However, few seem to base their claims on naturallyoccurring empirical data, but rather (much like the DCTs of Blum-Kulka, House and Kasper, 1989b) on 'pen and paper tasks' or controlled experiments. There is also little agreement between these typologies.

Antaki (1994) offers a critique of much of this literature and questions the evidence that people actually use "the excuses and justifications so painstakingly classified". He further suggests that "it is pointless to have such an elaborate inventory when it is impossible to identify utterances that represent each category, and that a priori category construction prejudices a view of what actually happens in talk" (1994:67). While Antaki's focus is conversational data and the co-construction of dialogic joint action that that entails, we would nevertheless align ourselves with these views since we share his commitment to a data-driven approach. This does also have its limitations. We cannot claim that the categories we develop and explain here will have universal applicability to requests as a whole, just that they have relevance to this particular discourse situation. In the words of Heider (1958:8), we recognize "the manifold of qualitative differences" in the situatedness of interaction.

In this study, we use the term ACCOUNT as a superordinate for the conjunction of the Heider-Austinian 'personal excuses' and 'environmental justifications'. For us, accounts refer to the invoked circumstances that the individual making the request sees as providing reasonable mitigation for the accountableness of the untoward requesting event (we provide examples in section 4.2.6 below) and our analysis explores some of the situated qualitative differences between various different types of such mitigating circumstances. 


\subsection{Doing Self-Enhancement: BUT-JUSTIFICATIONs (J-BUTS)}

In this section it is necessary to provide an explanation of the related (but currently less well known) concept that Davies, Merrison and Goddard (2007) have called 'BUT-JUSTIFICATIONS' (or J-BUTS). The definition that they provide (2007:57 original emphasis) is this:

\section{BuT-JUSTIFICATIONS}

I may have done something for which I need to apologize, but I'm doing other things that make me a good student/person.

While they originally arose from a study of apologising for some offence $(x)$, we have continued to find the notion of J-BUTS useful in explicating the current corpus of requests since a request is, itself, an imposition (which is a type of offence). Essentially, because they are acts in which $p$ attempts to enhance their own good standing by making $o$ aware of $p$ 's claimed 'good'-ness, $p$ effectively changes the environment in which the offence exists into one in which $o$ now knows that $p$ is 'good'. In such an environment (or at least so $p$ must hope), while the offence $(x)$ remains absolutely unchanged, the positive sentiment ('good'will) $p$ might consequently feel towards $o$ makes $x$, relatively, more justified.

The following example illustrates the type of behaviour that we are interested in: ${ }^{5}$

(1) $\mathrm{A} 05^{6}$

Dear FN,

My name is FN LN and I'm a student in your Communication: A Linguistics Approach class. Unfortunatly this week I have caught a bug on the bus and am unable to attend your tutorial session today. Please, if there is any extra work that was given, could I get a copy [so that I am up to date $]_{\mathrm{J}-\mathrm{BUT}-1}$ ?

Very sorry, [normally I would pull myself together because I know how important attendance is to overall grades, but it takes me nearly two hours to get to Griffith and another two hours to get home. $]_{\mathrm{J}-\mathrm{Bu}-2}$ [This tute is the only thing on my timetable today so it's the best oppotunity for me to rest before going to work on the weekend. $]_{\text {J-BUT-3 }}$

Much enjoyed your class yesterday and look forward to more of this very interesting topic.

\section{$\mathrm{FN}(\mathrm{NN})$}

After the student has requested that her lecturer provide her with any extra materials from the missed class, she proffers J-BUT-1 claiming that she does so because she wishes to be "up to date" (which would be congruent with them being a good student). Thereafter, she indicates in J-BUT-2 that she is the sort of person who would normally do four hours travelling to attend a single tutorial. Immediately after this, there is J-BUT-3 which suggests that the student plans to use the time away from class doing resting in preparation for her weekend paid

\footnotetext{
${ }^{5}$ All e-mails have been anonymised, with names being replaced by address terms, for example FN (First Name), LN (Last Name), NN (Nick Name). Where appropriate, sensitive personal information has been replaced by a summary, for example $<$ medical condition $>$. Where necessary, the use of bold signifies any material which we consider to constitute a request, underlining signifies ACCOUNTS, double-underlining signifies SELF-DISCLOSURE and the use of italics signifies BUT-JUSTIFICATION. We highlight particular phenomena of interest using [brackets]. In all other respects (e.g. spelling and punctuation), e-mails are reproduced verbatim.

${ }^{6}$ A05 represents the $5^{\text {th }}$ e-mail from the Australian corpus, B30 the 30 th e-mail in the British corpus and so on.
} 
employment. Through this account she is orienting herself to a student identity where juggling studies with part-time employment is acknowledged as the reality of student life for many in Australian universities. In taking the position that part-time work commitments are in some sense on par with study commitments without seeking the lecturer's approval, then, the student also adopts a stance of interdependent egalitarianism rather than deferential dependence (see section 5).

Having explained what we mean by BUT-JUSTIFICATIONS and ACCOUNTS, some may reasonably be wondering whether making this distinction is sufficiently advantageous. We leave the answering of that potential criticism to Davies, Merrison and Goddard (2007):

It may be that both ACCOUNTS and BUT-JUSTIFICATIONS should be seen as ways of building equity: certainly, both can be used to improve the standing of the speaker $[p]$ in the eyes of the addressee $[o]$. However, we would argue that there is a fundamental difference in the function of ACCOUNTS and BUT-JUSTIFICATIONS. ACCOUNTS are used [...] [as] a way of saying that full blame should not be attributed, and thus [an ACCOUNT] mitigates the damage. In contrast, BUT-JUSTIFICATIONS are not necessarily tied to the offence in the same way [...] Instead, they work through enhancing [...] some aspect of [o's] identity. (Davies, Merrison and Goddard, 2007:57f., original emphasis)

Davies et al. offer further details about further differences between BUT-JUSTIFICATIONS and ACCOUNTS but for our current purposes, we merely summarise these differences in Table 1 below:

\section{[Insert Table 1 here]}

Having re-introduced this fine distinction between ACCOUNTS and BUT-JUSTIFICATIONS, we now widen our scope to explore the range of relational work employed during these oneshot e-mail requests.

\subsection{Equity and Equilibrium}

The notion of weights and measures is an ongoing metaphor in the study of linguistic politeness. It is perhaps most noticeable in Brown and Levinson's (1987) formula for the 'weightiness' of a Face Threatening Act (FTA): $\mathrm{W}_{x}=\mathrm{D}(\mathrm{S}, \mathrm{H})+\mathrm{P}(\mathrm{H}, \mathrm{S})+\mathrm{R}_{x}$ where the overall measure of an FTA $\left(\mathrm{W}_{x}\right)$ depends upon the social distance between interactants (D), the power that the hearer holds over the speaker $(\mathrm{P})$, and the absolute ranking of the imposition within the particular culture $\left(\mathrm{R}_{x}\right)$. However, we can also find these ideas espoused by Coulmas (1981:81) who suggests that apologies and thanks "balance politeness relations", by Leech (1983:125) who talks of a 'cost-benefit scale' and a "balance-sheet of the relation between $s$ [peaker] and $h$ [earer]", and by Holmes (1990:159), who talks of apologies as being speech acts "intended to remedy an offence [and] restore equilibrium". Of course, this is perhaps unsurprising, as much of the politeness literature has its heritage in the sociology of Goffman, whose "ritual equilibrium" (1967:45) concerns the remedial action which restores the balance between individuals (as well as between the individual and society): 
After an offense has occurred, the job of the offender is to show that it was not a fair expression of his attitude, or, when it evidently was, to show that he has changed his attitude to the rule that was violated. In the latter case, his job is to show that whatever happened before, he now has a right relationship - a pious attitude - to the rule in question, and this is a matter of indicating a relationship, not compensating a loss. Goffman (1971:118, original emphasis)

This uptake of Goffmanian tradition is not restricted to linguistics, however, and although we are linguists, we align ourselves with the notion of equity which Clark (1996:294) adopts from social psychology where each act has associated costs and benefits for each of the participants. Equity theory has two basic assumptions: (i) "that people in social situations try to maximise their outcomes - their benefits minus their costs" (1996:290); and (ii) that in doing so interactants try to maintain equity. So, as we have said earlier, "a request potentially benefits $[p]$ who makes the request, but imposes a cost on $[o]$ who fulfils it. Thus, in equity terms, $[p]$ now owes $[o]$ a debt equivalent to the cost incurred by the request" (Davies, Merrison and Goddard, 2007:54). Clark (1996) defines the Equity Principle as follows:

In proposing a joint project, speakers are expected to presuppose a method for maintaining equity with their addressees. (Clark, 1996:295)

It can take a lot of effort to maintain equity - indeed, as Goffman (1967:42) notes, "if a person wishes to sustain a particular image of himself [...] he must work hard for the credits that will buy this self-enhancement for him". The interesting question, then, is how equity is maintained. We return to this very question in section four.

\section{Methodology}

\subsection{Building the corpora of requests}

The data used for this research are a corpus of 190 e-mails (containing 264 requests) sent to two female members of academic faculty (one British, one Australian) by undergraduate students from their respective universities in the North of England and in Queensland, Australia.

The ethics process for the two sets of data was carried out differently, due to the data sets being collected in different times and different locations. For the British corpus of $100 \mathrm{e}-$ mails (collected in 2007), the students concerned were e-mailed to ask permission to use their correspondence as data. A copy of their e-mail was included in the request, and the general purpose (researching student requests) was explained. For the Australian corpus of 90 e-mails (collected in 2009) all students enrolled in a particular lecturer's courses were told about the research by e-mail, and they were asked for their permission to allow their correspondence to form a part of the resulting corpus. In both cases, there was an explicit commitment to anonymise all personal data. To withdraw their data from the study, students were required to actively respond - thus a 'passive consent' mechanism was used. In all cases, the authors of these e-mails were studying in their home country and were considered to be native speakers of English by the recipients of the e-mails.

The advantage of this method is that it can effectively sidestep the observer's paradox. The collection of the data was after the moment of production, and this process could not have influenced it. Neither were these e-mails solicited from the students, they came organically out of the institutional discourse context. This avoids many of the criticisms which have been levelled at DCT methodologies, such as constraining subjects' response 
choices and producing data which did not represent natural usage (see Holmes 1990 and Jaworski 1994 for a discussion of these issues). In addition, these e-mails gave us a situated discourse context. So, unlike typical DCTs we can see how the head request act is built up into an overall message which is shaped to achieve the sender's overall goal(s). The issue it does raise, however, is the process of identifying requests. Unlike a DCT, the function of a piece of language is not pre-specified for the analyst.

In Davies, Merrison and Goddard (2007) we raised the question of whether an utterance requires an overt lexical Illocutionary Force Indicating Device (IFID) to constitute an apology, and, more problematically, if so, what counts as an IFID. For such speech acts as apologies there are (at least to varying degrees of strength) potential contenders: I apologise, I'm sorry, I'm afraid, I regret, excuse me, forgive me, pardon me, unfortunately. Requests, however, are much more problematic. Presumably the canonical IFIDs are request and possibly ask (though we could, inter alia, also include Searle's (1979:14) beg, plead, pray, entreat), but interestingly, it transpires that in our combined corpus of 264 requests, only $3.4 \%$ use request/ask in the request itself. The point is that we are interested in the way(s) in which students attempt to get stuff done and while 'requesting' comes under the umbrella of that general activity, it does not begin to account for all of it.

Inducing actions in others can be done via IFIDs, but it can also be done by a whole host of methods (cf. Blum-Kulka, House and Kasper 1989a): outright direct imperative commands (please let me know if I'm going wrong anywhere); direct simple interrogatives (is there a deadline for changing my course?); indirect [modal verb + pronoun] interrogative frames (would you please consider this?, can you let me know if this is ok?, may I please have permission to enrol in this course?); (implicit) declarative hints (she said I should email you about my marks for the essay I had an extension on); (implicit) declarative statements of want/need (I really need some advice); and (implicit) declarative statements of states of knowledge (I was just wondering if you wanted us to write about Searle's development of the theory). ${ }^{7}$ Thus, in the words of Heider (1958:244), we are interested in the many ways in which "One person can induce another to do something by producing conditions of action in the other person".

IFIDs are clearly not the way forward. These do not provide the "necessary and sufficient conditions' to define a request or apology (or probably any other speech act) (cf. Robinson, 2004). The types of lists of criteria given by, for example, Olshtain and Cohen (1983) can be useful in the analysis process, but they will not identify a request. As we have argued elsewhere (Davies, Merrison and Goddard, 2007:45), the only true resource we have for identifying speech acts is "our own judgment as language users engaged in a culture". Both Jaworski (1994) and Holmes (1990) take this approach with regard to apologies, and it is even more necessary with regard to requests precisely because of the lack of indicative IFIDS in comparison to apologies.

For our data, the first stage was the intended recipient identifying them as a request. Thus it was a person engaged in the interaction who made the initial choice. All authors were involved in the final decision to include a particular e-mail within the corpus, and a very small number were excluded on the basis of ambiguities in the intended function of the email. It should be noted that no judgments were made about the perceived efficacy of the request: this paper is about students' constructions of their relationship with the institution and its staff, not whether these constructions are aligned with those judgements made by staff. All these requests were concerned with the institutional business of the university, and thus addressed staff in those roles, with a similar profile of request types across the two data

${ }^{7}$ These examples are all taken from the corpora under investigation. 
sets. ${ }^{8}$ The e-mails vary from requests which are merely affirmation-seeking, to those which need fuller replies or actions (such as confirming extensions, holding meetings) outwith the online context. As with our work on apologies, our intention was to collect a heterogeneous corpus (cf. section 2.1.1) which would enable a data-driven investigation of requests rather than simply applying previous analyses. This is particularly important given the relatively under-researched nature of online communication.

\subsection{Using the corpora of requests}

Our method was to comprehensively categorise everything within each e-mail within the corpora. We noted the presence of (and in many cases quantified) all of the following, here presented in the order they tended to appear in the e-mail themselves:

1. gender of student

2. subject line of the e-mail

3. term of address used to refer to lecturer (use of TITLE)

4. introductory self-identification

5. alerters

6. internal modification

a. IN/DIRECTNESS of request

b. syntactic CONTINGENCY (wondering if)

7. external modification
a. ACCOUNTS
b. BUT-JUSTIFICATIONS
c. VIRTUAL GIFTS
i. APPRECIATIONS
ii. APOLOGIES

d. Geniality

i. CLOSENESS

ii. WELL-WISHING

iii. PERSONAL COMMON GROUND

e. COMMUNAL COMMON GROUND

f. SELF-DISCLOSURE

g. 'OTHER' FACE-ORIENTED STRATEGIES

8. AGGRAVATORS

9. sign off

These categories were derived from the data (although were also informed by the system developed by Blum-Kulka, House and Kasper, 1989a), and all elements of every e-mail were classified. ${ }^{9}$ This detailed qualitative analysis has provided a reasonably comprehensive picture of the way in which each request was built. While we have considered some aspects of internal modification (DIRECTNESS/INDIRECTNESS; syntactic CONTINGENCY), our main

\footnotetext{
${ }^{8}$ In the British corpus of e-mails, there were 54 requests for action $(35.5 \%), 74$ requests for information (48.7\%), and 24 requests for affirmation (15.8\%). In the Australian corpus, we found 54 requests for action $(48.2 \%), 41$ requests for information $(36.6 \%)$, and 17 requests for affirmation $(15.2 \%)$. All the action and information requests lay within the bounds of normal activities for academics in the institutions in question. ${ }^{9}$ The definition of these categories essentially follows that of Blum-Kulka, House and Kasper (1989a) unless otherwise indicated in the discussion in section two (i.e. in particular for ACCOUNTS and BUT-JUSTIFICATIONS). We have also introduced two new broader categories based on our data analysis, namely, GENIALITY and VIRTUAL GIFTS as we believe the strategies within these categories to have important affinities with each other, as we discuss further in section 4 .
} 
analysis focuses on external modification (Blum-Kulka, House and Kasper's 'supporting moves') including the use of ACCOUNTS, BUT-JUSTIFICATIONS, VIRTUAL GIFTS, GENIALITY, appeals to COMMUNAL COMMON GROUND, SELF-DISCLOSURE, as well as TITLES and AGGRAVATORS, the latter two of which we treat as part of the speech event but not strictly speaking the speech act itself. ${ }^{10}$ As becomes clear in the next section, this was where the cultural construction of student identities and the staff-student relationship in the UK and Australia was most differentiated. And looking at these requests through this wide-angle lens allowed us to see them as speech events rather than just speech acts.

\section{Results}

The analyses in this section are predominantly quantitative: we focus on those categories where we uncovered what we considered to be interesting differences across the two corpora. $^{11}$

The aspects of internal modification we present here are IN/DIRECTNESS and one type of syntactic CONTINGENCY. The types of supporting external modification in the order that we present them are: APOLOGIES; use of TITLES; AGGRAVATORS; COMMON GROUND; ACCOUNTS; SELF-DISCLOSURE; and BUT-JUSTIFICATIONS. In this section, we confine our activity to providing exemplification of these categories and showing the magnitude and direction of the cross-cultural comparative quantitative results. In section 5 we discuss what we believe are the implications of these observations.

\subsection{Internal Modification: the nature of the speech act}

\subsubsection{Directness of Requests}

Following Blum-Kulka, House and Kasper (1989a), the level of directness of requests can be broadly divided into three categories: direct (i.e. syntactically marked as a request), conventionally indirect (i.e. use of modal expressions routinely associated with requests), and non-conventionally indirect requests (i.e. arise through implicature). Results indicate that while conventional indirectness appears to be the favoured method (and constant) across both corpora, there are differences in the directness of request head acts: there were more direct requests amongst the British emails and more implicit requests (via particularised implicatures) in the Australian data (Table 2). ${ }^{12}$

[Insert Table 2 here]

\subsubsection{Syntactic Contingency: (just) wondering ${ }^{13}$}

\footnotetext{
${ }^{10}$ The term AGGRAVATOR refers to a specific type of upgrader (cf. Blum-Kulka, House and Kasper 1989a) that increases the illocutionary force and thus impact of the request.

${ }^{11}$ While our corpus of 19,764 (10465+9299) words (from $190(100+90)$ e-mails constituting $264(152+112)$ requests) is of a manageable size for us to comprehensively code and analyse, and sufficiently large for some patterns to emerge, the corpus is too small for significance testing to be useful. Rather than use occurrences per million words or raw percentages, we instead enlist ratios to demonstrate differences across the corpora. We do not, however, generally discuss as noteworthy any ratios less than 1.2:1 (or 1:1.2). Where such lower ratios are reported, we do so in italics to indicate that status.

${ }_{12}$ All ratios reported in this paper are presented in the order Australian:British (A:B).

${ }^{13}$ Other forms of contingency were initially investigated in our analyses (such as the use of possible/possibility) but they did not produce any comparatively interesting differences across the two data sets and so are not discussed here.
} 
There appear to be roughly equal measures of marking syntactic contingency with 'wondering if' across both corpora, however there is a marked difference in the proportion of wondering that is hedged with 'just': British data are more hedged (Table 3).

[Insert Table 3 here]

\subsection{External Modification: the nature of the speech events}

\subsubsection{Giving Virtual Gifts: APOLOGIES}

There are more APOLOGIES in the British corpus: $\mathrm{A}[17 / 90]<\mathrm{B}[24 / 100]^{14}$. Ratio $=1: 1.27$. In the following example, there are two apologies, one orienting to the offence of not informing the lecturer about missing a class earlier (APOL-1), and the other orienting to the potential imposition for the lecturer involved in complying with this request (APOL-2). Both are instances of apology-prefaced actions, then, where "the action of apologizing is typically subordinate to the adjacency-pair action being pursued in the remainder of the turn" (Robinson, 2004:296), namely, an informing in the first and a request in the second.

(2) B46: Apology

\section{FN}

[Sorry that I haven't let you know sooner, $]_{\mathrm{APOL}-1}$ but I'm not able to attend the pragmatics class this week, as I will be in Newcastle all day Tuesday and Wednesday morning because my niece is getting christened. I thought that the christening was this time next month, and therefore during the Easter holidays, but I was mistaken, and only found out this weekend. [I am very sorry, $]_{\mathrm{APOL}-2}$ but if you could put any reading I need to do in my pidgeon hole, I will pick it up as soon as I can.

I hope this does not cause too much trouble

\section{FN LN}

\subsubsection{Doing Deference: use of recipient's professional TITLE}

Although both the Australian and British recipients of these e-mails each had a $\mathrm{PhD}$, there was a much higher incidence of students using professional TITLES in the British corpus, consistent with Formentelli's (2009) broader study of the use of address terms used by students to lecturers in British academic settings: $A[2 / 90]<B[19 / 100]$. Ratio $=1: 8.56$. An example is given below.

(3) B54: Use of Title

Dear [Dr. $]_{\text {TITLE }}$ LN,

\footnotetext{
${ }^{14}$ To account for the differently sized corpora, figures are presented as [Number of occurrences / Number of emails in the corpus].
} 
We're doing our presentation on Thursday at $11 \mathrm{am}$, would it be possible to have a tape player and an overhead projector to use please? Thank you!

$\mathrm{NN}(\mathrm{FN}) \mathrm{LN}$

Notably, there were almost no examples of the use of professional TITLES in the Australian corpus.

\subsubsection{Doing Something (soon): AGGRAVATORS}

What Duthler (2006) would call a bald and on record 'request for reply', we call an AGGRAVATOR. They can exist as explicit imperatives (as in A87) or also as more indirect assertions (as in B01):

(4) A87: Aggravator

Hi Professor. I was wondering if we were presenting in lecture or tutorial.

[Please let me know. $]_{\mathrm{AGG}}$

Sincerely,

FN LN

(5) B01: Aggravator

Dear FN,

My name is FN LN and I am a first year undergraduate currently studying Joint Honours in French and Linguistics. I was wondering if it would be possible to arrange a short appointment with you, at your convenience, since I would like to change my course at the end of this year and am not entirely sure how the process works. [I look forward to hearing from you. $]_{\mathrm{AGG}}$

Best Wishes,

\section{FN LN.}

Within their coding manual, Blum-Kulka, House and Kasper (1989b) call elements which increase the impact of the request 'upgraders'. These upgraders are further subcategorised into ten subtypes, one of which being 'time intensifiers'. What we call AGGRAVATORS occasionally combine a request for reply with such a time intensifier (as in B25).

(6) B25: Aggravator

Dr LN, Ive lost my headings for the coursework, could $\mathrm{u}$ email me them or something $[\text { asap }]_{\text {AGG }}$ please?

Thanks, FN LN

There are more AGGRAVATORS in the British corpus: $\mathrm{A}[11 / 90]<\mathrm{B}[17 / 100]$. Ratio $=1: 1.39$. 


\subsubsection{Doing ‘Being Friendly’: GENIALITY}

We take what we are calling GENIALITY to comprise CLOSENESS, WELL-WISHING and PERSONAL COMMON GROUND. Following Clark (1996:100-116), we take PERSONAL COMMON GROUND to relate to shared knowledge which, because of joint personally shared experience, is potentially exclusively mutual between $p$ and $o$. This contrasts with COMMUNAL COMMON GROUND which is assumed shared knowledge solely due to comembership of a given community (in our data, most often the university community). WELL WISHING represents instances of $p$ wishing $o$ well and CLOSENESS is used for situations in which $p$ appears to emphasise some air of solidarity between themselves and $o$ (for example by using in-group identity markers, colloquial lexis or emoticons and other typographical features associated with computer-mediated communication). Below, we offer some examples of these various instantiations of GENIALITY.

(7) A25: closeness

Subject: New student! Please help Hi there FN,

My name is FN LN I swapped in your 1003LAL Communication: A Linguistic Approach, on wednesday night and therefore missed the first lecture. I turned up to the tute the next day to acquire info on the lecture I missed, but realised it wasn't on!

If you get a chance could you please email me the readings for next week as it doesn't detail it in the course outline. I just don't want to fall behind in the first week of Uni, thanks $[\text { heaps }]_{\text {CLOSE-1 }}$ I hope to hear back from you [:) $]^{15}$ CLOSE-2 FN

(8) A12: well-wishing

Hola FN,

Sorry to bother you but I was just wondering if you could have a quick look at my basic outline for my essay. It is very very rough, but I just thought I had better run it by you to see if you thought it was feasible, and if you had any suggestions I would be extremely grateful!

[Have a lovely day, $]_{\mathrm{ww}}$

FN

\footnotetext{
${ }^{15}$ In the tagging of this item, the fact that it was a smiley face :) has been slightly obscured.
} 
(9) B49: Personal Common Ground

$\mathrm{FN}$,

I cant find [the book you mentioned when i came and asked you about cross-cultural politeness $]_{\mathrm{PCG}}$. I searched, 'cross-cultural politeness,'

'intercultural politeness,' 'politeness + cultures' e.t.c. was just wondering whether you have any other suggestions or have found what the title is? thanks FN LN

There is proportionately more GENIALITY in the Australian corpus: A[31/90] > B[28/100]. Ratio $=1.23: 1$.

\subsubsection{Doing Group Membership: COMMUNAL COMMON GROUND}

There are also more instances of references to COMMUNAL COMMON GROUND (cf. "orienting move" in Woodfield and Economidou-Kogetsidis, 2010:1010) in the Australian corpus: $\mathrm{A}[13 / 90]>\mathrm{B}[10 / 100]$. Ratio $=1.44: 1$. Two examples of doing group membership in this way are illustrated below, one from each corpus.

(10) A29: Communal Common Ground

\section{Hi FN,}

[I know the Intercultural Communication course is already full, $]_{\mathrm{CCG}}$ however now that I have finalised my timetable and I am taking two subjects at UQ, this is the only linguistics subject that does not clash with my timetable. Is is possible for me to still enrol in this course?

Many Thanks

\section{FN LN}

\section{(11) B12: Communal Common Ground}

[I know Friday isn't a favoured day in the Ling department so I thought I would use email!! $]_{\mathrm{CCG}}$

I know you don't highlight a particular book to purchase in your reading list but I would like to buy one or two books on discourse analysis, even if they are general and don't cover EVERY single area. Was just wondering if there is one or if there are one or two that you recommend?

Thanks Dr.LN.

Best Wishes,

FN LN

Mobile: 07987654321 


\subsubsection{Doing Mitigation: ACCOUNTS}

We have distinguished between four types of accounts: INSTITUTIONAL (usually relating to something within the university or at least an educational community of practice); HEALTH (relating to ill health of the student); EMPLOYMENT (relating to employment outside the university); and PERSONAL (relating to issues concerning the student's personal life). These four types fall into two sub-categories: those over which students arguably have some control (PERSONAL) and those over which they do not (EMPLOYMENT, HEALTH and INSTITUTIONAL). In reverse order, we provide examples of each.

INSTITUTIONAL ACCOUNTS made reference to practices, policies or events within the university itself, as seen in the two examples below.

(12) A28: Institutional Account

Hello,

My name is FN LN, I'm on Gold Coast campus and my student number is S1234567. I've just enrolled into 1003LAL Communication: A Linguistic Approach tonight. I'm aware I've already missed the first lecture, and although I have enrolled tonight, I can't make it to the first tutorial tomorrow (Thursday) morning because I already have work commitments that I can't change in such late notice. I look forward to meeting you next Wednesday morning, I hope this is okay. [I've just been mucked around as the Uni let me enroll into a 2nd year course which I wasn't aware it was a 2nd year course and so on. $]_{\text {I- }}$ ACC But now it has all been swapped I'll be seeing you soon. Would you be able to let me know if I have missed anything important within the first lecture and tute?

Thanks,

FN

(13) B16: Institutional Account

Dear Dr. LN,

I was just wondering about the personal tutor system in the linguistics department. [ $\underline{I}$ don't think I have been assigned one, $]_{\text {I-ACC }}$ but I may well have missed a meeting or something so it's probably my own fault!

If you could let me know if I have one (and obviously who it is) or if I don't, when I will be assigned one as I have a couple of things that I would like to discuss at some point in the near future.

Many thanks,

\section{FN LN}

HEALTH ACCOUNTS often relate to non-attendance or requests for extensions. In both corpora, medical professionals may be invoked (see examples 12 and 13), but only in the Australian data do HEALTH ACCOUNTS generally also collocate with explicit mention of medical certification (example 13). The latter is not a consequence of differences in 
institutional requirements for documentation, however, as both universities require such evidence (see section 5).

(14) B64: Health Account

\section{Dear FN,}

I would like to arrange a meeting to discuss my degree course. I would like to do either joint honours in Linguistics and <other subject> or single honours Linguistics. [I won't be able to do a minor programme as I was diagnosed with $<$ medical condition $>$ last term and I am on a course to cobat it, which lasts until next July. My doctor is Dr LN at the $<$ name of clinic $>$. $]_{\mathrm{H}-\mathrm{ACC}}$ Please tell me how I go about changing my course.

Yours truly,

\section{FN LN}

(15) A09: Health Account

\section{Hi FN,}

I am writing to inform you that $[\underline{I}$ have been unwell this week. I have a medical certificate from my doctor (it is attached to this email). $]_{\mathrm{H}-\mathrm{ACC}}$

I was wondering if I could have an extention until Tuesday $5 \mathrm{pm}$ please?

Kind regards

FN

EMPLOYMENT ACCOUNTS occur only in the Australian corpus: $A[7 / 90]>B[0 / 100]$.

(16) A28: Employment Account

Hello,

My name is FN LN, I'm on Gold Coast campus and my student number is S1234567. I've just enrolled into 1003LAL Communication: A Linguistic Approach tonight. I'm aware I've already missed the first lecture, and although I have enrolled tonight, I can't make it to the first tutorial tomorrow (Thursday) morning [because I already have work commitments that I can't change in such late notice. $]_{\text {E-ACC }}$ I look forward to meeting you next Wednesday morning, I hope this is okay. I've just been mucked around as the Uni let me enroll into a 2nd year course which I wasn't aware it was a 2nd year course and so on. But now it has all been swapped I'll be seeing you soon. Would you be able to let me know if I have missed anything important within the first lecture and tute?

Thanks, FN 
There are more PERSONAL ACCOUNTS (see examples 17 and 18 below) in the British corpus: $\mathrm{A}[30 / 90]<\mathrm{B}[41 / 100]$. Ratio $=1: 1.23$.

\section{(17) A52: Personal Account}

\section{Dear FN,}

I am writing to update you on my current situation and ask for a bit of advice.

[Because of the kind of return plane ticket I bought to come over to Europe, I first had to book my return date for before my exchange was over, then change that date once I got over here. The earliest date I could get to come back after June is the 7th of August, $]_{\mathrm{P}-\mathrm{ACC}}$ meaning I'm going to miss the first 2 weeks of second semester.

I'm enrolled in your syntax class and I'm a little bit worried about missing so many classes. I was wondering how much of the semester I will be missing in those first two weeks, and if you think there would be anything I could do to catch up quickly, or start preparing something earlier so I'm not so far behind?

Thanks so much and see you soon,

FN

(18) B46: Personal Accounts

\section{FN}

Sorry that I haven't let you know sooner, but I'm not able to attend the pragmatics class this week, as [I will be in Newcastle all day Tuesday and Wednesday morning because my niece is getting christened. $]_{\mathrm{P}-\mathrm{ACC}-1}[\underline{\mathrm{I}}$ thought that the christening was this time next month, and therefore during the Easter holidays, but I was mistaken, and only found out this weekend. $]_{\text {P-ACC-2 }}$ I am very sorry, but if you could put any reading I need to do in my pidgeon hole, I will pick it up as soon as I can.

I hope this does not cause too much trouble

FN LN

There are no particularly reportable quantificational differences in any of the third-party accounts except for EMPLOYMENT ACCOUNTS which are found only in the Australian corpus: $\mathrm{A}[7 / 90]>\mathrm{B}[0 / 100] .^{16}$

\subsubsection{Doing Being Hopeless \& Ineffectual: SELF-DISCLOSURE}

SELF-DISCLOSURE relates to the revealing of information which might indicate a negative image of self. Although instances were found in both corpora, there is more SELF-DISCLOSURE in the British corpus: $\mathrm{A}[8 / 90]<\mathrm{B}[27 / 100]$. Ratio $=1: 3.04$.

\footnotetext{
${ }^{16}$ The Australian:British ratio of HEALTH ACCOUNTS across the data sets is, admittedly, 1.56:1. However, because occurrences in both corpora are based on relatively small $\mathrm{N}(\mathrm{A}[7 / 90]>\mathrm{B}[5 / 100])$ we do not feel warranted in making claims based on this particular difference.
} 
Hi FN,

I am writing in regards to the results of my last exam, I am not sure if you have had the time to go through any of them yet, but I am concerned about my results as I was unable to finish the test.

I studied a lot for the class and enjoyed the subject more than any of the other areas of linguistics, but [unfortunately, I don't think that will be apparent in my final work. If I am looking at a failing grade, $]_{\text {SD-1 }}$ I would like to know if there is any further work I can do to make up for what I didn't finish in the exam.

I haven't had to request this before so I am not sure if there is a certain procedure that needs to be taken. [To be honest I was aiming for a high distinction but my main priority is passing at this point in time. $]_{\text {SD-1 }}$

\section{FN LN}

\section{(20) B40: Self Disclosure}

FN,

$<$ lecturer $1>$ might have been in touch with you, but [i'm doing the syntactic theory module this semester and after two weeks i'm about pulling my hair out! $]_{\mathrm{sD}-1}[\underline{\underline{\mathrm{i} \text { don't }}}$ think a semester has gone by when i haven't changed a module, but this is ridiculous $]_{\mathrm{SD}-2}$, [as mush reading as i do for it i don't think i'll ever be able to keep up! $]_{\text {SD-3 }}$ [ though it'd be similar to intro to grammar but it's lot harder and i only achieved 41 for grammar. $]_{\mathrm{SD}-4}$ i've spoken to <module leader> about it but there's nothing specific she can help me with, [the whole of the stuff she covers is way over my head! $]_{\mathrm{SD}-5}$

basically, i asked $<$ lecturer $1>$ about numbers for scioloinguistics and he told me they were practically full but to get in touch with you. my other options are language acquisition, psycholinguistics (not sure if running?) and pragmatics/morphology, which is obvioiusly not ideal.

i can come and see you next week to talk about whether there is a chance of me swapping.

many thanks

fn $\ln$

\subsubsection{Doing Self-Enhancement: BUT-JUSTIFICATIONS (J-BUTS)}

We have already introduced BUT-JUSTIFICATIONS in section 2.3. Here we make a finer distinction. While we absolutely maintain that J-BUTS seem to address either the institutional role of 'good student' or the more generic role of 'good person', and that they operate as means of self-enhancement, whereas ACCOUNTS orient to offence mitigation, we need to make a refinement to our earlier (Davies, Merrison and Goddard, 2007) notion of J-BUTS, namely that we now wish to distinguish between two distinct types: 
(1) BUT-JUSTIFICATION (state) e.g. "I AM worried about $P$ " [J-BUT-BE]

(2) BUT-JUSTIFICATION (action) e.g. "I'm DOING some worthy $Q$ ” [J-BUT-DO] (where actions (material processes) imply states (relational processes))

Thus, in the example from section 2.3 we now have the following analysis of J-BUTS:

(21) A05: J-BUT-1-BE + J-BUT-2-DO + J-BUT-3-DO (BE+DO+DO)

\section{Dear FN,}

My name is FN LN and I'm a student in your Communication: A Linguistics Approach class. Unfortunatly this week I have caught a bug on the bus and am unable to attend your tutorial

session today. Please, if there is any extra work that was given, could I get a copy [so that I am up to date? $]_{\mathrm{J}-\mathrm{BUT}-1-\mathrm{BE}}$ ?

Very sorry, [normally I would pull myself together because I know how important attendance is to overall grades, but it takes me nearly two hours to get to Griffith and another two hours to get home. $]_{\text {-BUT-2-Do }}$ [This tute is the only thing on my timetable today so it's the best oppotunity for me to rest before going to work on the weekend. $]_{\mathrm{J}-\mathrm{BUT}-3-\mathrm{DO}}$

Much enjoyed your class yesterday and look forward to more of this very interesting topic.

\section{FN (NN)}

We add a further example from the British corpus. J-BUT- 1 is a claim that $p$ enjoys linguistics ( $p$ likes what $o$ likes, and therefore $o$ should value $p$ ). J-BUT-2 claims that $p$ is better at linguistics ( $p$ is good at what $o$ is good at, and therefore $o$ should value $p$ ). Finally, J-BUT-3 shows that $p$ is committed to linguistics ( $p$ values what $o$ values, and therefore $o$ should value $p$ ).

(22) B45: J-BUT-1-BE + J-BUT-2-BE + J-BUT-3-DO (BE+BE+DO)

\section{To Doctor LN,}

I am writing from Italy on my year abroad to ask about the possibility of changing the weighting of my degree in the fianal year. At the moment my degree is Joint Honours Linguistics and Italian. [Seeing as I enjoy Linguistics much more] $]_{\text {J-BUT-1-BE, }}$ and [am much stronger at it than Italian $]_{\mathrm{J}-\mathrm{BUT}-2-\mathrm{BE}}$, [I'd like to take all my credits in Linguistics in my final year. $]_{\mathrm{I}-\mathrm{BUT}-3-\mathrm{DO}}$ 
Would there be any problem in me doing so? How would I go about changing? I'm assuming I will have to move parent department from JHML too. Also, when will the module choices for next year be available?

I would really appreciate any advice and info you have on the subject.

Best Wishes,

FN LN

987-654-321

There are more J-BUTS of both types in the Australian corpus: J-BUT-BE A[26/90] > $\mathrm{B}[22 / 100]$, Ratio $=1.26: 1$; J-BUT-DO A[32/90] $>$ B[22/100], Ratio = 1.62:1.

\subsubsection{Summary of Results for External Modification}

The results for the ratios in section 4.2 are summarised in Table 4.

[insert Table 4 here]

\section{Discussion}

In this section we discuss the findings reported above. We do so in order to provide support for the two overall theses that were introduced at the beginning of this paper (and which are reiterated here for the sake of clarity). The first relates to the degree of perceived entitlement to make a request (which is structural in nature), while the second relates to the overall orientations of the request event design (which are specific to these particular cultural contexts).

\section{(I) Perceived entitlement}

the degree of perceived entitlement to make a requesting act is inherent within the construction of the entire requesting event

\section{(II) EgaLitaRIANiSM vs. DEPENDENCE}

the British e-mail data display an orientation towards deferential dependence and the Australian e-mail data towards interdependent egalitarianism

The distinction between orientations to egalitarianism/dependence is made manifest in several ways: how students construct the relationship between themselves and their lecturers, how they construct their position in the institutional hierarchy and how they construct themselves as students. Institutional expectations also have an impact on the way in which requests are built: the market value for different types of mitigation is not necessarily consistent across cultures.

The British students orient to a perceived institutional hierarchy more than their Australian counterparts. This can be seen most explicitly through their use of professional titles like $D r$ : they use these over 8 times as much as the Australian students, which is by far the largest differential across the two corpora. It is also evidenced through other means. In terms of external modification, this can be seen through the relative use of apologies: the British corpus contains more of these than the Australian one. If requests are understood as 
impositions - inducing others to act on your behalf - then apologies are an explicit recognition of that social breach. In Davies, Merrison and Goddard (2007:60) we argued for the utility of a financial metaphor, where requests "are typically seen as potential debits" and that apologies can be a delicate way of acknowledging that debt, and so go some way to rebuilding credit. What their use indexes is a more formal relationship between the interactants, where debts are explicitly recorded.

In contrast, Australian students construct their relationship with academics as more egalitarian. In the building of their requests, they use more GENIALITY (CLOSENESS, WELLWISHING and PERSONAL COMMON GROUND). As such, they seem to be treating faculty more as social peers rather than indexing a differential hierarchical status. This is reinforced by greater use of COMMUNAL COMMON GROUND in the Australian corpus - shared experience is emphasised at the expense of institutional hierarchy. This would seem to be in keeping with Goddard's (2006:66) claim that Australians ('Aussies') embrace a social attitude which values (claiming) equality between interactants even in situations where there are recognisable differences in social roles and status:

Many commentators have identified something like "egalitarianism" as an Australian social ideal, and despite the widening gap between rich and poor, most commentators recognise that an "egalitarianism of manners", to use historian John Hirst's (1998:208) phrase, is still an important part of Australian social life.

This is not to say that Australian students make undue assumptions about their entitlements. Curl and Drew (2008) observed that using 'wondering' in the context of a request seemed to mark contingency - it indexed an uncertainty of entitlement in the requester. Like their callers to an after-hours telephone line for a British primary care physician's (GP) practice, both sets of students used constructions like 'wonder if' in building their requests; indeed, in the region of one quarter of all our requests employed 'wondering' in their composition. Such a finding is interesting given that Curl and Drew (2008:135) claim that this marking of contingency is "nearly absent in some other [non-GP] institutional databases of requests". And we would certainly agree with their assessment that "it is not an institutional setting per se that triggers the use of more contingent forms [...] rather, callers construct themselves as potentially lacking entitlement through their use of these forms" (Curl and Drew, 2008:148, emphasis added). However, we again see a slight differential construction across the two corpora. This 'lack of entitlement' is especially evinced by the British students, as demonstrated by their additional use of the lexical downgrader just. This again seems to highlight a greater orientation to deference in the British data.

Somewhat less obviously, we would also argue that some of the differences we see in the use of implicitness and the use of AGGRAVATORS also orient towards this contrasting construction of the lecturer-student relationship. While conventional indirectness is the most common strategy across the two corpora - and fairly constant throughout both - there is a difference in the degree of directness. The Australian students use both fewer direct requests and more implicit requests, thus choosing to frame their requests in a more indirect way. This may seem at odds with our thesis that British students are more deferential, given the longstanding purported relationship between indirectness and degree of perceived politeness in the research literature. ${ }^{17}$ However, Brown \& Levinson (1987:130) argue that there are times when using direct language can, in fact, mark deference - when one is "bothering important persons for favours". By "coming rapidly to the point, avoiding further imposition of

\footnotetext{
17 This is often attributed to Brown \& Levinson (1987) (see, for example, Blum-Kulka, 1987) but is also apparent in Leech (1983).
} 
prolixity and obscurity" the students orient towards their lecturer's right to autonomy by not demanding further inferential work on their behalf.

This orientation to 'lecturers as important people' can also arguably be seen in the greater use of AGGRAVATORS by the British students. More standardly, one might expect the use of AGGRAVATORS to index either a close relationship (intimacy allows forthright imposition) or where the requester holds institutional power over the requestee. This, however, would be in conflict with the students' overall construction of their relationship with their lecturers. One potential solution is to see their behaviour as an orientation to the humility associated with deference. The British students seem to be constructing an identity which ennobles the lecturer while humbling themselves. They do so by effectively claiming the request they are making is either beyond the rights or skills of someone in their (low) position, or would be an onerous deal for them. In contrast, fulfilling the request is considered to be well within the means of the esteemed academic, perhaps even a 'mere bagatelle'. To use a not unrelated example to illustrate this, one author of this paper recently received an e-mail from a student requesting an academic reference for a postgraduate teaching application in which the student wrote "I'm sure you can write these in minutes by now!". This rather over-optimistic evaluation could - in context - only be interpreted as part of a piece of identity construction in which the academic is positioned as possessing much greater skills and acumen than the student. While it is not an AGGRAVATOR in its own right, it does seem to set up a context in which one could be used for such an easy and quick task.

Differences can also be seen in the way in which students in the two cultures construct their own identities. In keeping with the hierarchical relationship that they build with their lecturers, British students construct themselves as dependents who are not always able to manage their institutional role as student effectively. They use more personal accounts as mitigation, positioning themselves as more culpable as individuals for their need to petition their teachers. In addition, more SELF-DISCLOSURE is used by these students, too. They are prepared to reveal information which will indicate a negative image of themselves. We interpret this as the British students constructing for themselves a hopeless and ineffectual self-identity (cf. Biesenbach-Lucas 2007:61) - at least in terms of their institutional identity.

In contrast to this, the Australian students build for themselves a professional identity both within and outwith the institutional context. Their mitigation draws more on third-party resources - institutional, medical and employment accounts - thus deflecting the true culpability elsewhere. They also avoid the use of SELF-DISCLOSURE in comparison to their British counterparts. This is in keeping with the kind of identity that Goddard proposes would fit with "An Aussie 'tough attitude' cultural script" (2006:71, original italics): "People who openly, frequently and fulsomely express how bad they feel about events or conditions of daily life face condemnation as whingers or sooks [people lacking spirit or self confidence] $[\ldots]$ because in doing so they expose their emotional vulnerability and violate the traditional ethos of toughness and practicality" (Goddard 2006:71). The Australian students thus project themselves as competent inhabitants of their institutional role.

It is interesting to note a qualitative distinction in the HEALTH ACCOUNTS which seems to delicately index this differential between these two identities. While British students use ill health as a reason to request extensions, leave of absence and so forth, they never explicitly offer supporting documentation. This is in absolute contrast to the Australian students who immediately offer such evidence, and even orient to its absence if (for some reason) it is not available. This can be seen in the following example from the Australian data where the student orients to the cultural norm of medical certification being required, and then appears to accept culpability and the consequential fact that they "will lose marks for lateness": 
Hello

This is FN LN s1234567

I unfortunately missed my date of presentation (wk 12) [due to illness. $]_{\mathrm{H}-\mathrm{ACC}}[\mathrm{I}$ have no doctors certificate and am understanding that I will lose marks for lateness. $]_{\mathrm{CCG}}$ However the assignment is complete and I was wondering if I could present it in wk 13 or at some other time.

Regards

FN LN

It should be noted that this difference in behaviour is not as a result of different formal requirements: the British students are also required to produce documentation in such circumstances $-\mathrm{a}$ fact that they are reminded of at frequent intervals and via many different sources. In most cases, the academic's reply to an e-mail using a HEALTH ACCOUNT in the British context would include a request for medical certification. Thus, Australian students seem to be explicitly demonstrating their competence through delivering what is expected of them in this institutional role.

Australian students can also build this competent identity through reference to their societal roles outwith the university context. Using issues with work as mitigation for a request shows that the requester is a productive member of society, and in that sense can claim to be their lecturer's peer. This resource is simply not available to the British students. This is not because British students do not undertake paid work, but rather because students in the UK are constructed by the institution as 'full-time students': this does not allow for a work identity outside the educational context. In the case of these particular students, the British University explicitly disallows employment issues as a valid mitigating circumstance. This runs completely counter to the Australian situation, where lecturers are expected to be "accommodating" to students who have paid work commitments. Thus, these British students are not only barred from using employment as mitigation, they are also effectively barred from using its societal value in constructing their identity.

One finding that does not apparently fit with the kind of 'Aussie cultural script' that Goddard (2006) describes is the Australian students' greater use of BUT-JUSTIFICATIONS as a resource for self-enhancement. He claims that there is an Australian tendency "to play down anything 'special' about oneself, including one's abilities, achievements, and experiences" (Goddard 2006:71) which can be seen as an overall desire to discourage "wanting other people's admiration" (2006:68, original italics), although this is generally in the context of responding to compliments and the like or avoiding what might be seen as boasting or "bignoting" oneself (the latter of which tends to occasion mockery if not avoided; cf. Bousfield and Haugh, this issue; Haugh, 2010). Of course, there may well be a difference between the kind of reaction an individual wants to evoke in public and private channels. We have previously argued in Davies, Merrison and Goddard (2007:20ff) that students may use BUTJUSTIFICATIONS in e-mail precisely because it offers a private opportunity to construct a 'good-student' identity, whereas to do so in public could fatally compromise other aspects of their identity. Given Goddard's analysis of the Australian cultural context, it may be that such private channels are an even more important resource for Australian students. 
In sum, then, our corpus has provided a glimpse of what it is to 'do being a student' in two different English-speaking contexts. We would not claim that what we have offered constitutes anything like a full analysis. The true richness of this data lies in the various combinations of internal and external modification in the building of these speech events, and this we have barely touched upon (as yet). However, comparing these two corpora in this way has led us ('Brits' and 'Aussies' alike) to interrogate our assumptions about how university life works in our two countries and how this has affected the ways in which our students have constructed themselves in constructing their requests.

\section{Conclusion: on obligation}

Heider's exploration of requesting and commanding has offered a useful insight into the nature of obligation; he describes a request or command as an attempt to "induce another to do something by producing conditions of action in the other person" (1958:244). These conditions can be achieved in a variety of ways by creating an environment in which the recipient is more likely to grant the request. This, as we have demonstrated in this paper, can be achieved through multiple resources (including, but not restricted to, ACCOUNTS, SELFDISCLOSURES, and BUT-JUSTIFICATIONS).

Following Heider (1958:249ff), when a person feels they ought to do something, ought forces are acting upon them. During a request, one of the possible ways of inducing these forces is to remind a recipient of their duty to follow the Equity Principle and repay a prior debt to $p$. We call this EQUITY-type of obligation an 'OUGHT-2' force. Another way of inducing an ought force is to admit that you are too weak to help yourself: an obligation of $o$ towards $p$ may also be an ought force induced by the difficulty (or at least claimed difficulty) of achieving a solution by $p$ compared to the difficulty (or, rather, ease) of providing $a$ solution for $p$, by $o$. We call this WEAK-type of obligation an 'OUGHT-1' force. The greater/smaller the magnitude of the difference between $p$ 's difficulty and $o$ 's difficulty, the greater/smaller the OUGHT-1 force, and thus, the more/less obligated $o$ will be to grant the request. It is whatever is done by $o$ in response to the obligation (be it induced by an OUGHT-1 or an OUGHT-2 force) that attempts to redress the equilibrium between $p$ and $o$.

In our data, there appears to be a distinction between the predominance of strategies employed by the requesters in the different contexts. In the British context, students seem to orient to claims that they are weak and of a lower social standing - that they are feeble and ineffectual (at least within the parameters of their CofP) and therefore, because they are in the purview of their institutionally-empowered lecturers, they appear to construct their e-mails to induce OUGHT-1 help. In the Australian context, obligation seems to be presumed to be more of a matter of a peer-to-peer phenomenon. These students do not seem to orient to any low status within their institution but instead to claims that they, too, are contributing members of the wider culture and therefore, because they construct their lecturers as members of the same egalitarian-driven community, they appear to construct their e-mails to induce OUGHT- 2 help.

But in both contexts, in constructing their e-mails to academic staff, students regularly appear to put a lot of (we would argue, culturally-relevant) work into getting their requests granted - into getting their stuff done. These data clearly demonstrate that doing politeness is a cultural as well as a language-based phenomenon: knowing how to do politeness in English is not enough - we also have to know how to do politeness in a particular cultural and situational context. 


\section{Acknowledgements}

For allowing us access to her e-mail inbox, we give virtual gifts to Susana Eisenchlas; for providing RA-funding, we greatly appreciate York St John University; and for the very many useful comments on various earlier drafts, we deferentially acknowledge the insight from numerous conference delegates, the anonymous reviewers for the Journal of Pragmatics and members of the Language \& Identities in Inter-Action (LIdIA) research unit at York St John University (especially Chris Hall, Rachel Wicaksono and Ollie Hambling-Jones). For all remaining shortcomings, while the authors are communally personally culpable, each blames the next on the list. They do, however, apologise for their collective misdemeanours. Finally, AJM and JJW would like to publicly note the geniality of St John Takeaway York, for its part in Jack and Andrew's own internal modifications which regularly sustained them throughout their many overnight writing sessions.

\section{References}

Antaki, Charles, 1994. Explaining and Arguing: The Social Organization of Accounts. Sage, London.

Arundale, Robert B., 2006. Face as relational and interactional: a communication framework for research on face, facework, and politeness. Journal of Politeness Research 2, 193-216. Austin, John L., 1961 [1956]. A plea for excuses. In: Urmson, James O., Warnock, Geoffrey J. (Eds.), Philosophical Papers. Oxford University Press, London, pp. 123-152.

Austin, John L., 1975 [1962]. How to Do Things With Words (2nd edition). Oxford: Clarendon Press.

Benoit, William L., 1995. Accounts Excuses and Apologies: A Theory of Image Restoration Strategies. State University of New York Press, Albany, NY.

Biesenbach-Lucas, Sigrun, 2007. Students writing emails to faculty: An examination of epoliteness among native and non-native speakers of English. Language Learning and Technology 11, 59-81.

Blum-Kulka, Shoshana, House, Juliane, Kasper, Gabriele, 1989a. Investigating cross-cultural pragmatics: An introductory overview. In: Blum-Kulka, Shoshana, House, Juliane, Kasper, Gabriele (Eds.), Cross-Cultural Pragmatics: Requests and Apologies. Ablex, Norwood, NJ, pp.1-34.

Blum-Kulka, Shoshana, House, Juliane, Kasper, Gabriele (Eds.), 1989b. Cross-Cultural Pragmatics: Requests and Apologies. Ablex, Norwood, NJ.

Brown, Penelope, Levinson, Stephen C., 1987. Politeness: Some Universals in Language Use. Cambridge University Press, Cambridge.

Bunz, Ulla, Campbell, Scott W, 2004. Politeness accommodation in electronic mail. Communication Research Reports 21, 11-25.

Clark, Herbert H., 1996. Using Language. Cambridge University Press, Cambridge.

Coulmas, Florian, 1981. Poison to your soul: Thanks and apologies contrastively viewed. In: Coulmas, Florian (Ed.), Conversational Routine. Mouton, The Hague, pp. 69-91.

Culpeper, Jonathan, 2008. Reflections on impoliteness, relational work and power. In: Bousfield, Derek, Locher, Miriam A. (Eds.), Impoliteness in Language. Mouton de Gruyter, Berlin, pp. 17-44.

Curl, Traci S., Drew, Paul, 2008. Contingency and action: A comparison of two forms of requesting. Research on Language and Social Interaction 41, 129-153.

Davies, Bethan, L., 2007. Grice's Cooperative Principle: Getting the meaning across. Journal of Pragmatics 39, 2308-2331. 
Davies, Bethan L., Merrison, Andrew John, Goddard, Angela, 2007. Institutional apologies in UK higher education: Getting back into the black before going into the red. Journal of Politeness Research 3, 39-63.

Drew, Paul, 2009. The unrequited relationship between Bush and Blair: on making offers in conversation. Public Lecture at York St John University, $4^{\text {th }}$ November 2009.

Duthler, Kirk. W., 2006. The politeness of requests made via email and voicemail: Support for the hyprerpersonal model. Journal of Computer-Mediated Communication 11, 500 521.

Eckert, Penelope, McConnell-Ginet, Sally, 1992. Think practically and look locally: Language and gender as community-based practice. Annual Review of Anthropology, 21, 461-490.

Economidou-Kogetsidis, Maria, 2011. "Please answer as soon as possible": Pragmatic failure in non-native speakers' e-mail requests to faculty. Journal of Pragmatics 43: 3193-3215.

Eelen, Gino, 2001. A Critique of Politeness Theories. Manchester: St. Jerome.

Formentelli, Maicol, 2009. Address strategies in a British academic setting. Pragmatics 19, 179-196.

Fukushima, Saeko, 2008. Pictographs in Japanese e-mail requests. The Tsuru University Graduate School Review 12, 13-29.

Goddard, Cliff, 2006. "Lift your game Martina!": deadpan jocular irony and the ethnopragmatics of Australian English. In: Goddard, Cliff (Ed.), Ethnopragmatics: Understanding Discourse in Cultural Context. Mouton De Gruyter, Berlin, pp. 65-97.

Goffman, Erving, 1967 [1955]. On face-work: An analysis of ritual elements in social interaction. In: Goffman, Erving, Interaction Ritual: Essays on Face-to-Face Behavior. Pantheon Books, New York, pp. 5-45.

Goffman, Erving, 1971. Remedial Interchanges. In: Goffman, Erving, Relations in Public: Microstudies of the Public Order. Penguin, Harmondsworth, pp. 95-187.

Grice, H. Paul, 1975. Logic and conversation. In: Cole, Peter, and Morgan, Jerry L. (Eds.), Syntax and Semantics, vol. 3. Academic Press, New York, pp. 41-58.

Hambling-Jones, Oliver, Merrison, Andrew John, this issue. Inequity in the pursuit of intimacy: An analysis of British pick-up artist interactions. Journal of Pragmatics.

Haugh, Michael, 2003. Anticipated versus inferred politeness. Multilingua 22, 397-413.

Haugh, Michael, 2007. The discursive challenge to politeness theory: an interactional alternative. Journal of Politeness Research 3, 296-317.

Haugh, Michael, 2010. Jocular mockery, (dis)affiliation and face. Journal of Pragmatics 42, 2106-2119.

Haugh, Michael, 2012. Conversational interaction. In: Allan, Keith, Jaszczolt, Kasia M. (Eds.), The Cambridge Handbook of Pragmatics. Cambridge University Press, Cambridge, pp. 251-273.

Haugh, Michael, Bousfield, Derek, this issue. Mock impoliteness, jocular mockery and jocular abuse in Australian and British English. Journal of Pragmatics.

Heider, Fritz, 1958. The Psychology of Interpersonal Relations. Lawrence Erlbaum, Mahwah, NJ.

Herring, Susan. C., 2002. Computer-mediated communication on the Internet. Annual Review of Information Science and Technology 36, 109-168.

Hirst, John, 1998. Egalitarianism. In: Hirst, John, Macintyre, Stuart (Eds.), The Oxford Companion to Australian History. Oxford University Press, Melbourne, pp. 208-209.

Ho, Victor, 2010. Constructing identities through request e-mail discourse. Journal of Pragmatics 42, 2253-2261. 
Ho, Victor, 2011. What functions do intertextuality and interdiscursivity serve in request email discourse? Journal of Pragmatics 43, 2534-2547.

Holmes, Janet, 1990. Apologies in New Zealand English. Language in Society 19, 155-199. Jaworski, Adam, 1994. Apologies and non-apologies: Negotiation in speech act realization. Text 14, 185-2016.

Jensen, Astrid, 2009. Discourse strategies in professional e-mail negotiation: A case study. English for Specific Purposes 28, 4-18.

Leech, Geoffrey N., 1983. Principles of Pragmatics. London: Longman.

Merrison, Andrew John, Davies, Bethan L., 2007. Getting stuff done: Institutional requests in UK higher education e-mail. Paper presented at the Third International Symposium on Politeness, University of Leeds, UK, $4^{\text {th }}$ July 2007.

Mills, Sara, 2003. Gender and Politeness. Cambridge University Press, Cambridge.

Olshtain, Elite, Cohen Andrew D., 1983. Apology: A speech act set. In: Wolfson, Nessa, Judd, E. (Eds.), Sociolinguistics and Language Acquisition, pp. 18-35. Newbury House, Rowley MA.

Robinson, Jeffrey D., 2004. The sequential organisation of 'explicit' apologies in naturally occurring English. Research on Language and Social Interaction 37, 291-330.

Rogers, Priscilla S., Lee-Wong, Song Mei, 2003. Reconceptualizing politeness to accommodate dynamic tensions in subordinate-to-superior reporting. Journal of Business and Technical Communication 17, 379-412.

Schelling, Thomas, C. 1960. The Strategy of Conflict. Harvard University Press, Cambridge MA.

Schönbach, Peter. 1990. Account Episodes: The Management or Escalation of Conflict. Cambridge University Press, Cambridge.

Searle, John R., 1979 [1975]. A taxonomy of illocutionary acts. In: Searle, John R., Expression and Meaning: Studies in the Theory of Speech Acts. Cambridge University Press, Cambridge, pp. 1-29.

Searle, John R., 2001. Rationality in Action. MIT Press, Cambridge, MA.

Semin, Gün R., Manstead, Antony S. R., 1983. The Accountability of Conduct: A Social Psychological Analysis. Academic Press, London.

Wardvogel, Joan, 2007. Greetings and closings in workplace email. Journal of ComputerMediated Communication 12, 456-477.

Watts, Richard, 2003. Politeness. Cambridge University Press, Cambridge.

Wenger, Étienne, 1998. Communities of Practice. Cambridge University Press, New York.

Woodfield, Helen and Economidou-Kogetsidis, Maria, 2010. 'I just need more time': a study of native and non-native students' requests to faculty for an extension. Multilingua 29, $77-118$. 


\begin{tabular}{ll}
\hline ACCOUNTS [Mitigation] & BuT-JUSTIFICATIONS [Enhancement] \\
\hline Oriented directly to offence & Need not be oriented to offence \\
\hline $\begin{array}{l}\text { Oriented to societal norms (what } \\
\text { 'counts' as an offence) }\end{array}$ & $\begin{array}{l}\text { Oriented to individual (institutional) } \\
\text { identities }\end{array}$ \\
\hline $\begin{array}{l}\text { Need to be acceptable to recipient(s) and } \\
\text { to be of appropriate value (and have to } \\
\text { be relevant in context) }\end{array}$ & $\begin{array}{l}\text { Generic institutional acceptability and } \\
\text { value. }\end{array}$ \\
\hline $\begin{array}{l}\text { Not context-bound. } \\
\text { extra benefit (credit) to identity/equity }\end{array}$ & $\begin{array}{l}\text { Not tied to offence: equity/identity } \\
\text { credit can be (potentially) greater than } \\
\text { offence debit }\end{array}$ \\
\hline $\begin{array}{l}\text { Concerns public identity: for } \\
\text { consumption by peers and others }\end{array}$ & $\begin{array}{l}\text { Concerns potentially private identity: } \\
\text { only for consumption by intended } \\
\text { recipient(s) }\end{array}$ \\
\hline $\begin{array}{l}\text { Open to verification (by recipient(s) or } \\
\text { by others). }\end{array}$ & Less open to verification. \\
\hline
\end{tabular}

Table 1. Characteristics of ACCOUNTS and BUT-JUSTIFICATIONS (adapted from Davies, Merrison and Goddard, 2007:58). 


\begin{tabular}{lcccc}
\hline & $\begin{array}{c}\text { Direct } \\
\text { Requests }\end{array}$ & $\begin{array}{c}\text { Conventionally } \\
\text { Indirect Requests }\end{array}$ & $\begin{array}{c}\text { Implicit } \\
\text { Requests }\end{array}$ & $\begin{array}{c}\text { TOTAL } \\
\text { Requests }\end{array}$ \\
\hline Australian & $\begin{array}{c}31.25 \% \\
(\mathrm{~N}=35)\end{array}$ & $\begin{array}{c}41.96 \% \\
(\mathrm{~N}=47)\end{array}$ & $\begin{array}{c}26.78 \% \\
(\mathrm{~N}=30)\end{array}$ & $\begin{array}{c}100 \% \\
(\mathrm{~N}=112)\end{array}$ \\
\hline corpus & $40.13 \%$ & $41.45 \%$ & $18.42 \%$ & $100 \%$ \\
British & $(\mathrm{N}=61)$ & $(\mathrm{N}=63)$ & $(\mathrm{N}=28)$ & $(\mathrm{N}=152)$ \\
\hline A:B ratio & $1: 1.28$ & $1.01: 1$ & $1.45: 1$ & - \\
\hline
\end{tabular}

Table 2. Typology of Requests. 


\begin{tabular}{lcccc}
\hline & $\begin{array}{c}\text { Contingency: } \\
\text { 'wondering' }\end{array}$ & $\begin{array}{c}\text { Hedged } \\
\text { Contingency: } \\
\text { 'just wondering' } \\
(\mathrm{N})\end{array}$ & $\begin{array}{c}\text { Contingency: } \\
\text { 'wondering' }\end{array}$ & $\begin{array}{c}\text { Hedged } \\
\text { Contingency: } \\
\text { 'just wondering, } \\
(\%)\end{array}$ \\
\hline $\begin{array}{l}\text { Australian } \\
\text { corpus }\end{array}$ & 27 & $6 / 27$ & 24.11 & $22.22 \%$ \\
\hline $\begin{array}{l}\text { British } \\
\text { corpus }\end{array}$ & 35 & $12 / 35$ & 23.03 & $34.29 \%$ \\
\hline A:B ratio & - & - & $1.05: 1$ & $1: 1.54$ \\
\hline
\end{tabular}

Table 3. Syntactic contingency: (just) wondering. 


\begin{tabular}{rrll}
\hline & $\begin{array}{c}\text { Australian } \\
\text { Corpus }\end{array}$ & $:$ & $\begin{array}{l}\text { British } \\
\text { Corpus }\end{array}$ \\
\hline APOLOGIES & 1 & $:$ & $\mathbf{1 . 2 7}$ \\
\hline TITLES & 1 & $:$ & $\mathbf{8 . 5 6}$ \\
\hline AGGRAVATORS & 1 & $:$ & $\mathbf{1 . 3 9}$ \\
\hline GENIALITY & $\mathbf{1 . 2 3}$ & $:$ & 1 \\
\hline COMMUNAL COMMON GROUND & $\mathbf{1 . 4 4}$ & $:$ & 1 \\
\hline PERSONAL ACCOUNTS & 1 & $:$ & $\mathbf{1 . 2 3}$ \\
\hline EMPLOYMENT ACCOUNTS & $\mathbf{N = 7}$ & & $\mathrm{N}=0$ \\
\hline SELF-DISCLOSURE & 1 & $:$ & $\mathbf{3 . 0 4}$ \\
\hline J-BUT-BE & $\mathbf{1 . 2 6}$ & $:$ & 1 \\
\hline J-BUT-DO & $\mathbf{1 . 6 2}$ & $:$ & 1
\end{tabular}

Table 4. Ratios of External Modifications (ratio not possible for EMPLOYMENT ACCOUNTS). 